\title{
BMJ Open Risk factors for mortality of adult patients with COVID-19 hospitalised in an emerging country: a cohort study
}

\author{
Alfonso M Cueto-Manzano (D) ,' María C Espinel-Bermúdez (D) ,' \\ Sandra O Hernández-González (D) , ${ }^{1}$ Enrique Rojas-Campos (D) , \\ Arnulfo H Nava-Zavala (D) , ${ }^{1}$ Clotilde Fuentes-Orozco (D) ,1 \\ Luz Ma A Balderas-Peña (1) , ${ }^{1}$ Alejandro González-Ojeda (D) ,' \\ Laura Cortes-Sanabria (1) ,' Mario A. Mireles-Ramírez (1) ,2 \\ José J Ramírez-Márquez (1) , ${ }^{3}$ Porfirio E Martínez-Gutiérrez (1) , \\ Maribel Ávila-Morán (1D , ${ }^{5}$ Ramón I De-Dios-Pérez (D) , ${ }^{6}$ Carlos Acosta-Ramírez (i) ,7 \\ Hugo R Hernández-García (iD) ${ }^{8}$
}

To cite: Cueto-Manzano AM, Espinel-Bermúdez MC, Hernández-González SO, et al. Risk factors for mortality of adult patients with COVID-19 hospitalised in an emerging country: a cohort study. BMJ Open 2021;11:e050321. doi:10.1136/ bmjopen-2021-050321

- Prepublication history for this paper is available online. To view these files, please visit the journal online (http://dx.doi. org/10.1136/bmjopen-2021050321).

Received 18 February 2021 Accepted 06 July 2021

\section{Check for updates}

(C) Author(s) (or their employer(s)) 2021. Re-use permitted under CC BY-NC. No commercial re-use. See rights and permissions. Published by BMJ.

For numbered affiliations see end of article.

\section{Correspondence to} Dr Alfonso M Cueto-Manzano; a_cueto_manzano@hotmail. com

\section{ABSTRACT}

Objective To describe mortality of in-hospital patients with COVID-19 and compare risk factors between survivors and non-survivors.

Design Prospective cohort of adult inpatients.

Setting Tertiary healthcare teaching hospital in Guadalajara, Mexico.

Participants All patients with confirmed COVID-19 hospitalised from 25 March to 7 September 2020 were included. End of study: 7 November 2020.

Primary outcome measures Patient survival analysed by the Kaplan-Meier method and comparison of factors by the log-rank test. Mortality risk factors analysed by multivariate Cox's proportional-hazard model.

Results One thousand ten patients included: 386 (38\%) died, $618(61 \%)$ alive at discharge and six $(0.6 \%)$ remained hospitalised. There was predominance of men (63\%) and high frequency of overweight-obesity $(71 \%)$; hypertension (54\%); diabetes (40\%); and lung (9\%), cardiovascular $(8 \%)$ and kidney diseases (11\%); all of them significantly more frequent in non-survivors. Overweight-obesity was not different between groups, but severity of disease (Manchester Triage System and quick Sequential Organ Failure Assessment) was significantly worse in nonsurvivors, who were also significantly older ( 65 vs 45 years, respectively) and had haematological, biochemical, coagulation and inflammatory biomarkers more altered than survivors. Mortality predictors were invasive mechanical ventilation (IMV; OR 3.31, p<0.0001), admission to intensive care unit (ICU; OR 2.18, $p<0.0001$ ), age (OR 1.02, $p<0.0001$ ), Manchester Triage System (urgent OR 1.44, $\mathrm{p}=0.02$; immediate/very urgent $\mathrm{OR} 2.02, \mathrm{p}=0.004)$, baseline $C$ reactive protein (CRP; OR 1.002, $p=0.009)$ and antecedent of kidney disease (OR 1.58, $p=0.04$ )

Conclusions Mortality in hospitalised patients with COVID-19 in this emerging country centre seemed to be higher than in developed countries. Patients displayed a high frequency of risk factors for poor outcome, but the need for IMV, ICU admission, older age, more severe disease at admission, antecedent of kidney disease and higher CRP levels significantly predicted mortality.
Strengths and limitations of this study

- Several variables such as the optimal use and efficacy of antivirals and antibiotics, adherence to high standards of supportive therapies (particularly invasive mechanical ventilation or renal replacement therapies) or others could not be exhaustively analysed in this study as data were collected exclusively by means of the electronic medical records.

- On the other hand, a large sample size from a single centre supports the internal validity of results, but extrapolation to other settings needs to be investigated.

- Due to the scarcity of data in one of the geographical area most affected by the COVID-19 pandemic, our results gain special relevance.

\section{INTRODUCTION}

By January 2020, a novel coronavirus, SARS-CoV-2 (previously known as 2019$\mathrm{nCoV}),{ }^{1}$ was identified as the cause of a pneumonia outbreak in Wuhan, China, which was later named as COVID-19 by the WHO. ${ }^{2}$ Due to its widespread infectivity and high contagion rate, the virus infected and caused death of thousands of people in China and then spread to the rest of the world. SARS-CoV-2 has become a global health threat, ${ }^{3}$ and by the beginning of December 2020, COVID-19 has caused the death of 1496075 people worldwide and infected almost more than 65 million. ${ }^{4}$

Nowadays, Latin America has a high burden of the disease, with five countries within the top 20 with more diagnosed cases and mortality. ${ }^{4}$ Due to economical restrictions and lack of resources, some countries in this area are facing difficulties in implementing 
diagnostic strategies for a large number of people and providing care for severe cases. Thus, having reliable data gains major relevance for administrators and governments to take oriented decisions, researchers to perform studies and the general population to take preventive actions and learn about the progression of disease in their particular setting. Many international and national organisations provide daily numbers of COVID-19 cases, recoveries and deaths ${ }^{4-6}$; however, local data with greater details are essential to know the profile of the pandemic, the clinical course of the disease and mortality risk factors in such countries. Surprisingly, few data about these issues are available at the present time in our country or the Latin America region.

Therefore, the aim of this study was to describe mortality rate of in-hospital patients with laboratory-confirmed COVID-19, as well as to compare the risk factors and main characteristics between survivors and non-survivors.

\section{METHODS}

This study was a prospective cohort of adult ( $\geq 18$ years old) inpatients from the Hospital de Especialidades, Centro Médico Nacional de Occidente, Instituto Mexicano del Seguro Social (IMSS). The latter is a tertiary care teaching centre and one of the three hospitals converted to treat patients with COVID-19 of the social security system (IMSS) in the state of Jalisco. All patients were screened, managed and hospitalised according to the WHO Interim Guidance for COVID-19. ${ }^{7}$ All patients with a confirmed diagnosis of COVID-19 hospitalised since 25 March 2020 (the first case admitted in our hospital) and 7 September 2020 (date in which the hospital stopped to be exclusively a COVID-19 centre) were included in this analysis. The end of the study was established on 7 November 2020, and the final status of patients was classified as alive, dead or remaining hospitalised.

Sociodemographic, clinical, treatment and outcome variables were collected from electronic medical records. Laboratory data were collected from the central laboratory electronic record of our hospital. Laboratory confirmation of SARS-CoV-2 was performed by the Laboratorio de Apoyo a la Vigilancia e Investigación Epidemiológica, Centro de Investigación Biomédica de Occidente, the only authorised laboratory for processing respiratory specimens within the IMSS in our region. Nasopharyngeal and oropharyngeal specimens were used for testing by real time reverse transcriptase (RT)-PCR with the Berlin protocol.

Baseline laboratory blood examinations included complete blood count, coagulation profile, blood chemistry, electrolytes and kidney and liver function tests by usual techniques. Creatine kinase, lactate dehydrogenase $(\mathrm{LDH})$, myocardial enzymes and $\mathrm{C}$ reactive protein (CRP) were measured by an enzymatic colorimetric method in a VITROS 4600 Chemistry System-Ortho Clinical Diagnostics. Ferritin was measured by chemiluminescence in an automated analyser LIAISON, DiaSorin, whereas D-dimer, procalcitonin and N-terminal pro b-type
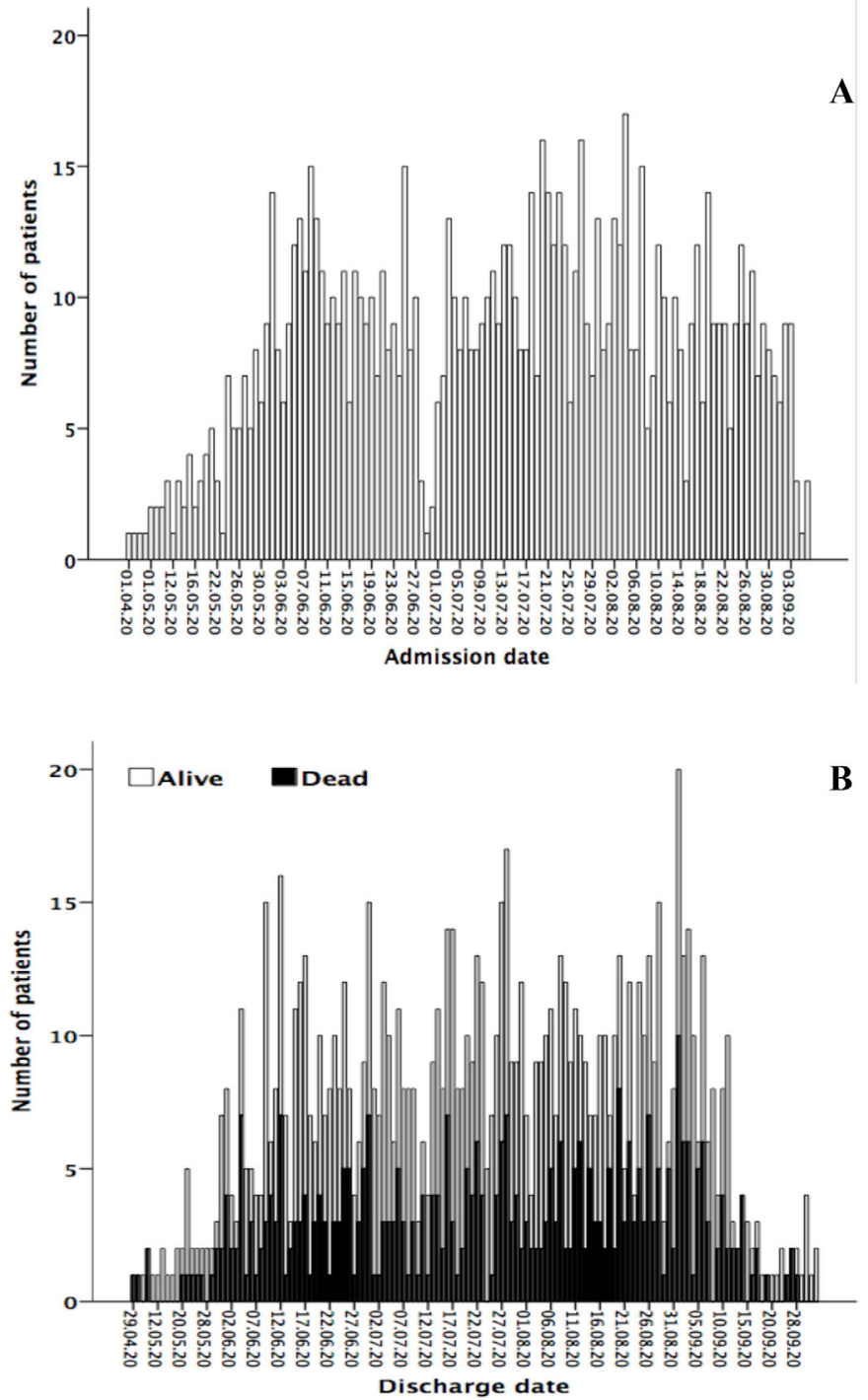

Figure 1 Number of admissions (A) and discharges (B) per day during the period of study.

natriuretic peptide were measured in an immunoanalyser VIDAS PC bioMérieux SA by enzyme-linked fluorescent assay. All patients had chest radiographs and/or CT scan. Protocol was approved by the local research committee (number: R-2020-1301-151). It was not possible to involve patients or the public in the design, conduct, reporting or dissemination plans of our research.

\section{Definitions}

Secondary infection was diagnosed when patients showed clinical symptoms or signs of pneumonia or bacteremia, and a positive culture of a new pathogen was obtained from lower respiratory tract specimens or blood samples after admission. ${ }^{89}$ Acute kidney injury was diagnosed according to the Kidney Disease: Improving Global Outcomes (KDIGO) clinical practice guidelines, ${ }^{10}$ and acute respiratory distress syndrome (ARDS) was diagnosed according to the Berlin definition. ${ }^{11}$ The illness severity was defined according to the Manchester Triage 
Table 1 Comparisons of demographical characteristics between non-survivors and survivors at admission

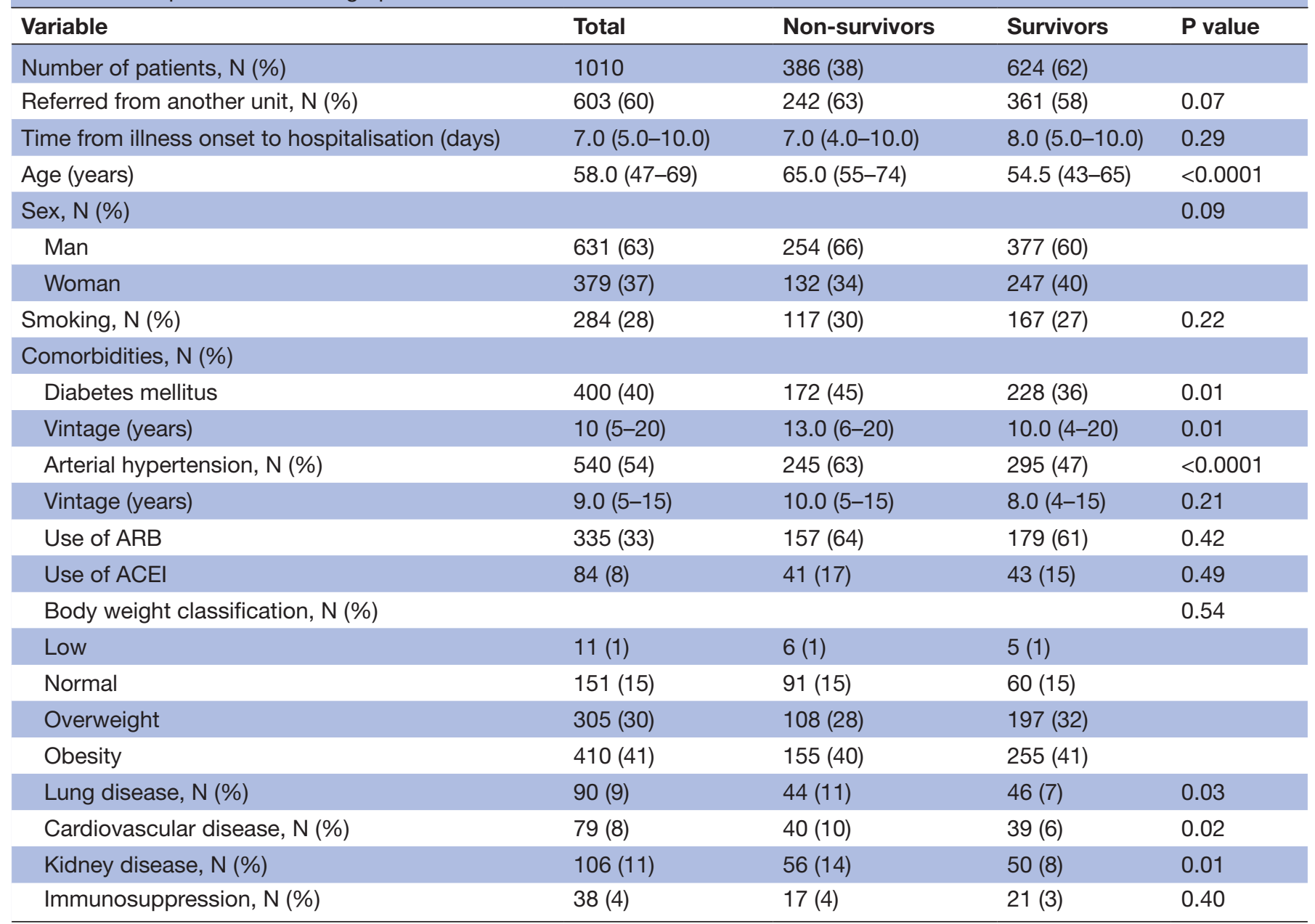

ACEI, ACE inhibitors; ARB, angiotensin receptor blockers.

System $^{12}$ and the quick Sequential Organ Failure Assessment (qSOFA) Score. ${ }^{13}$

\section{Patient and public involvement}

Due to the nature of the pandemic and severity of disease in hospitalised cases, patients and public were not involved neither in the development of research question and outcome measures nor in the design, recruitment and conduct of the study.

\section{Statistical analysis}

Quantitative variables are presented as median (IQR) and nominal ones as N (\%). Mann-Whitney U or $\chi^{2}$ tests were used to compare differences between survivors and non-survivors, in the case of quantitative and nominal variables, respectively. Analysis of patient survival was performed using the Kaplan-Meier method and comparison of factors by the log-rank test. ${ }^{14}$ Mortality risk factors were analysed by multivariate Cox's proportional-hazard model in which variables resulting as significant from the univariate analysis, or those considered relevant from the clinical point of view or previous published literature, were included (in a stepwise manner). A one-tailed $\mathrm{p}<0.05$ was considered statistically significant.

\section{RESULTS}

One thousand ten patients with confirmed COVID-19 were admitted to our hospital during the period of this report: $386(38.2 \%)$ died, $618(61.2 \%)$ were alive at discharge and six $(0.6 \%)$ remained hospitalised. Up to the end of follow-up, only 42 (4\%) were health workers. In all cases of death, the primary cause was related to acute respiratory distress due to SARS-CoV-2. Other pathologies mentioned as associated to death were unspecified pneumonia, acute kidney failure or exacerbated chronic kidney failure, arterial hypertension, diabetes mellitus, sepsis, obesity, pulmonary fibrosis and acute endocarditis. Figure 1 shows the number of patients per day admitted and discharged during the study period. In concordance with the observed in the general population of Mexico and the state of Jalisco, admissions started to increase by mid-May, reaching the maximum peak in the months of June and August and then observing a decrease by the 
Table 2 Comparisons of symptoms and clinical characteristics between non-survivors and survivors at admission

\begin{tabular}{|c|c|c|c|c|}
\hline Variable & Total & Non-survivors & Survivors & $P$ value \\
\hline \multicolumn{5}{|l|}{ Symptoms, N (\%) } \\
\hline Dyspnoea & $836(83)$ & $337(87)$ & $500(80)$ & 0.003 \\
\hline Cough & $688(68)$ & $254(66)$ & $434(70)$ & 0.21 \\
\hline Cephalea & $411(41)$ & $138(36)$ & $273(44)$ & 0.01 \\
\hline Upper airway symptoms & $411(41)$ & $162(42)$ & $249(40)$ & 0.52 \\
\hline Asthenia/adynamia & $498(49)$ & $176(46)$ & $322(52)$ & 0.06 \\
\hline Others (gastrointestinal, rash) & $545(54)$ & $210(54)$ & $335(54)$ & 0.81 \\
\hline Manchester Triage System, N (\%) & & & & $<0.0001$ \\
\hline Standard and non-urgent & $639(63)$ & $156(40)$ & $483(78)$ & \\
\hline qSOFA & & & & $<0.0001$ \\
\hline 0 & $311(31)$ & $81(21)$ & $230(37)$ & \\
\hline 1 & $560(55)$ & $220(57)$ & $340(55)$ & \\
\hline 2 & $122(12)$ & $69(18)$ & $53(8)$ & \\
\hline 3 & $17(2)$ & $16(4)$ & $1(0.2)$ & \\
\hline Temperature $\left({ }^{\circ} \mathrm{C}\right)$ & $37.0(36.5-37.4)$ & $36.9(36.5-37.1)$ & $37.0(36.5-37.5)$ & $<0.0001$ \\
\hline Pulse oximetry (\%) & $88(81-93)$ & $85(74-92)$ & $90(84-93)$ & 0.009 \\
\hline Respiratory rate (× min) & $22(20-25)$ & $23(20-26)$ & $22(20-25)$ & $<0.0001$ \\
\hline Systolic blood pressure (mm Hg) & $125(113-139)$ & $128(113-140)$ & $125(112-138)$ & 0.12 \\
\hline
\end{tabular}

qSOFA, quick Sequential Organ Failure Assessment.

last week of August until our hospital stopped to be an exclusive COVID-19 reference centre. Although a clear pattern was not observed, mortality of in-hospital patients with COVID-19 seemed to increase mainly since the last weeks of July.

Table 1 shows demographical characteristics of patients at admission. No differences were observed between survivors and non-survivors neither in the number of patients spontaneously arrived versus referred from another medical unit nor in the time from illness onset to hospitalisation. Median age was 58 years, but non-survivors were 10 years older than survivors. In both groups, there was a predominance of male sex and high frequency of comorbidities such as overweight and obesity (almost three-quarters of patients); diabetes mellitus and arterial hypertension (almost half of the patients each); and antecedents of pulmonary, cardiovascular and kidney disease (around 10\% each). All these comorbidities were more frequently observed in non-survivors, except for overweight and obesity. In patients with hypertension, intake of angiotensin receptor blockers (ARB) or ACE inhibitors (ACEI) was not different between groups.

Table 2 shows the comparison of symptoms and clinical findings between groups. Most frequently reported symptoms on admission were dyspnoea, fever and cough; dyspnoea was significantly more frequent in patients who died, whereas fever, cephalea and myalgia/arthralgia were more frequent in those who survived. Severity of disease was strongly associated with mortality evaluated either by the result of the Manchester Triage System or by the qSOFA Scale. At admission, median values of temperature and blood pressure were not remarkably altered in both groups, but respiratory rate was higher and pulse oximetry lower in patients who died at the end of follow-up.

Comparisons of laboratory and imaging findings on admission are shown in table 3. In general, at baseline, patients displayed data compatible with acute inflammatory response, including leukocytosis, lymphopenia, and high levels of procalcitonin, CRP and ferritin, all of them more remarkably altered in patients who died. Serum concentrations of glucose, urea, creatinine, aspartate aminotransferase, total creatine kinase and $\mathrm{LDH}$ were also significantly higher in non-survivors than in survivors. Additionally, non-survivors had higher levels of creatine kinase-MB, cardiac troponin I and N-terminal pro b-type natriuretic peptide, reflecting a more deteriorated cardiac function and a marked prothrombotic 
Table 3 Comparisons of laboratory and imaging findings between non-survivors and survivors at admission

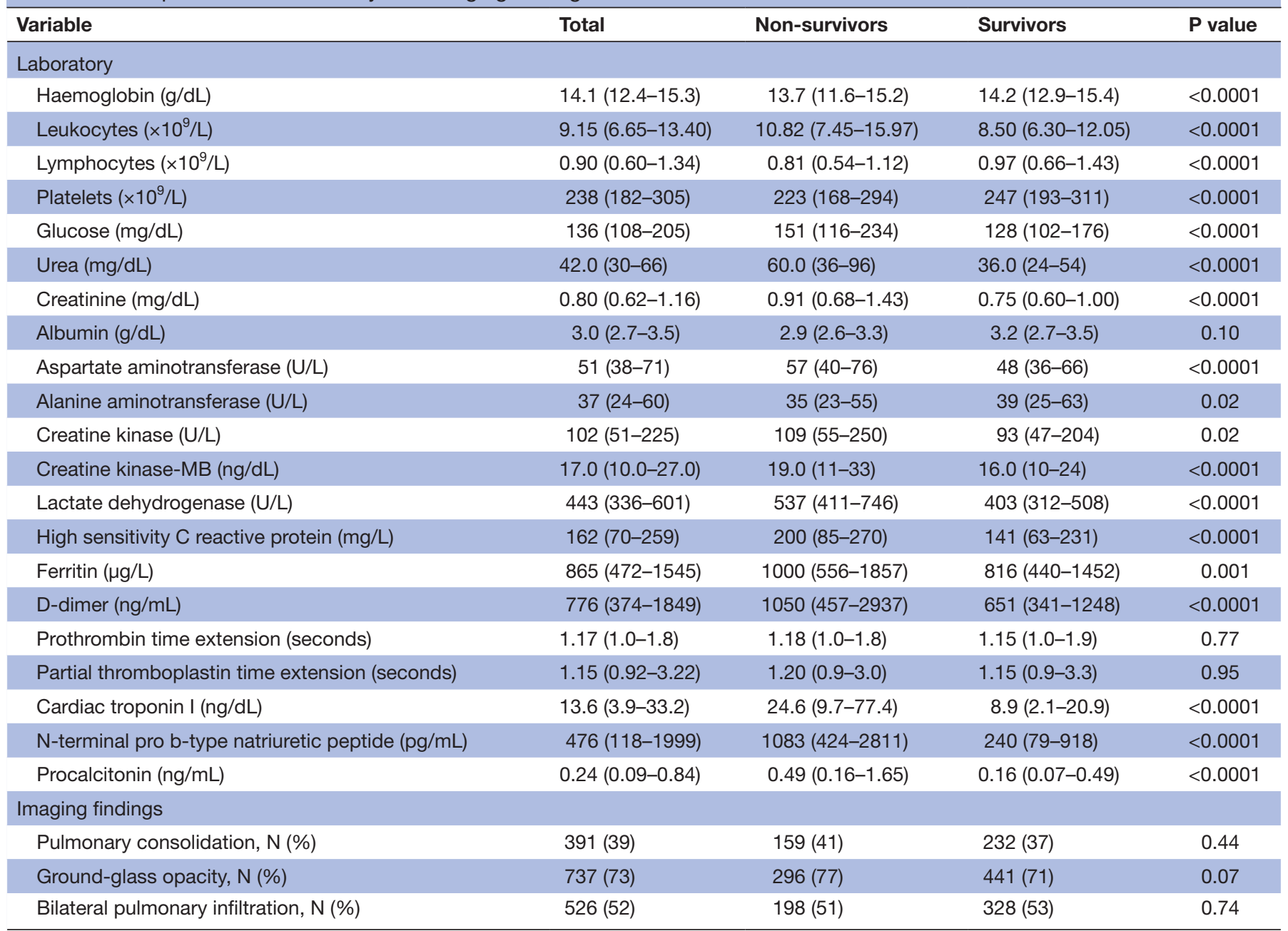

Creatine kinase-MB, creatine kinase isoenzyme MB

activity determined by higher concentrations of D-dimer than survivors. On the other hand, the presence of lung imaging findings compatible with COVID-19 (consolidation, ground-glass opacities and bilateral infiltrations) was reported in electronic records in about $40 \%-80 \%$ of cases each, but they were not different between groups.

Regarding the treatment (table 4), not many differences were found between groups. There was an extensive use of antibiotics and steroids (mostly dexamethasone), and it was higher in non-survivors. In particular, azithromycin was employed in around $25 \%$ and hydroxychloroquine in $6 \%$ of cases, without intergroup differences. Half of the patients had a record of use of antivirals, and virtually all consisted of lopinavir/ritonavir. Twelve patients received tocilizumab, and three of them died. In addition, almost $90 \%$ of patients in both groups had antithrombotic therapy prophylaxis; in our hospital, only enoxaparin was used for this purpose. Admission to intensive care unit (ICU) and invasive mechanical ventilation (IMV), as well as renal replacement therapy, were clearly more frequent in non-survivors than in survivors; median time from illness onset to initiation of IMV was not different between groups, but non-survivors had less time with this therapy than survivors. Moreover, the use of different types of renal replacement therapies was not different between groups.

Regarding the clinical outcomes (table 5), it was clear that development of respiratory failure and ARDS was significantly associated with higher mortality of patients with COVID-19, although time elapsed between illness onset and respiratory failure was shorter in survivors. Development of acute kidney failure (or exacerbation of chronic kidney disease) was also significantly associated with higher mortality, as well as secondary infection, coagulopathy and cardiovascular complications, although the latter three were observed in a smaller proportion than the first two complications. Median length of stay in ICU was similar between groups, whereas hospital length of stay and time elapsed from illness onset to the final event were 1 day longer in survivors.

Finally, in the multivariate Cox's proportional-hazard model (table 6) performed to identify variables that independently predicted mortality, the presence of IMV, admission to ICU, older age, more severe disease 
Table 4 Comparisons of main treatments received by non-survivors and survivors

\begin{tabular}{|c|c|c|c|c|}
\hline Variable & Total & Non-survivors & Survivors & $P$ value \\
\hline Antibiotics, N (\%) & $855(85)$ & $350(91)$ & $505(81)$ & $<0.0001$ \\
\hline Azithromycin & $247(25)$ & $90(23)$ & $157(25)$ & 0.53 \\
\hline Antivirals, N (\%) & $498(49)$ & $192(50)$ & $306(49)$ & 0.83 \\
\hline Steroids, N (\%) & $760(75)$ & $315(82)$ & $445(71)$ & $<0.0001$ \\
\hline Invasive mechanical ventilation (IMV), N (\%) & $298(29)$ & $254(66)$ & $44(7)$ & $<0.0001$ \\
\hline Time from illness onset to IMV (days) & $10.0(6.0-14.0)$ & $10.0(7.0-14.0)$ & $10.0(5.2-14.7)$ & 0.65 \\
\hline Time with IMV (days) & $9.0(4.2-15.0)$ & $9.0(4.0-13.0)$ & $14.0(9.0-27.0)$ & $<0.0001$ \\
\hline Renal replacement therapy, N (\%) & $59(6)$ & $49(13)$ & $10(2)$ & $<0.0001$ \\
\hline
\end{tabular}

classified by the Manchester Triage System, higher serum CRP at admission and antecedent of kidney disease were the only significant predictors for higher mortality in these patients.

\section{DISCUSSION}

The present study is one of the first reports of risk factors for COVID-19 mortality in Latin America. Two studies with smaller numbers of patients exclusively admitted to ICU reported a mortality of $52 \%$ in Mexico ${ }^{15}$ and $15 \%$ in Brazil. ${ }^{16}$ Our results indicate that, considering hospitalised patients both from the ICU and the ward, mortality in our setting may be higher than the reported in other parts of the world (12\%-28\%). ${ }^{17-21}$ Possible reasons for the high mortality rate in this population may include differences in thresholds for hospitalisation in our country; however, the presence of high-risk factors may also be involved and is noteworthy to mention.
Median age of patients from our setting was younger than informed in other series from the USA or Europe ${ }^{18-20}$; notwithstanding, non-survivors were 10 years older than survivors. Even though the Mexican general population had a high prevalence of comorbid conditions such as hypertension and diabetes, ${ }^{22}$ hospitalised patients with COVID-19 and particularly those who died had a remarkably higher frequency of such risk factors than those who survived. The use of ARB or ACEI as associated with higher, lower or similar risk for SARS-CoV-2 infection remains controversial ${ }^{23}$; in our study, their use was similar between groups. Mexico has one of the highest prevalence of overweight-obesity in the world, affecting $75 \%$ of adults, ${ }^{22}$ a percentage similar to the observed in these hospitalised patients, although proportions of overweight and obesity are inverted in the latter compared with the general population. Overweight-obesity, however, was not different between groups. Other comorbidities such

\begin{tabular}{llccc}
\hline \multicolumn{7}{l}{ Table 5 Comparisons of outcomes between non-survivors and survivors } & \multicolumn{5}{l}{} \\
\hline Variable & Total & Non-survivors & Survivors & P value \\
\hline Respiratory failure, N (\%) & $668(66)$ & $350(91)$ & $318(51)$ & $<0.0001$ \\
$\quad$ Time from illness onset to respiratory failure (days) & $7.0(4.0-12.0)$ & $8.0(5.0-12.0)$ & $7.0(4.0-11)$ & 0.04 \\
Acute respiratory distress syndrome, N (\%) & $408(40)$ & $364(94)$ & $44(7)$ & $<0.0001$ \\
Secondary infection, N (\%) & $105(10)$ & $74(19)$ & $32(5)$ & $<0.0001$ \\
Coagulopathy, N (\%) & $36(4)$ & $24(6)$ & $12(2)$ & $<0.0001$ \\
Acute kidney failure, N (\%) & $224(22)$ & $182(47)$ & $42(7)$ & $<0.0001$ \\
Cardiovascular complication, N (\%) & $53(5)$ & $39(10)$ & $14(2)$ & $<0.0001$ \\
Intensive care unit length of stay (days) & $9.0(5.0-15.0)$ & $9.0(5.0-14.0)$ & $10.0(5.0-17.0)$ & 0.36 \\
Hospital length of stay (days) & $10.0(6.0-15.0)$ & $9.0(4.0-15.0)$ & $10.0(7.0-15.0)$ & 0.01 \\
Time from illness onset to death, discharge or end of the & $17.0(12.0-23.0)$ & $17.0(10.0-23.0)$ & $18.0(13.0-24.0)$ & 0.005 \\
study (days) & & & &
\end{tabular}


Table 6 Results of the multivariate Cox's proportionalhazard model $\left(\chi^{2} 112.3, p<0.0001\right)$ to predict mortality in patients with COVID-19

\begin{tabular}{llll}
\hline Variable & OR & $95 \%$ Cl & P value \\
\hline $\begin{array}{l}\text { Invasive mechanical } \\
\text { ventilation }\end{array}$ & 3.31 & 2.32 to 4.74 & $<0.0001$ \\
$\begin{array}{l}\text { Intensive care unit } \\
\text { admission }\end{array}$ & 2.18 & 1.56 to 3.04 & $<0.0001$ \\
$\begin{array}{l}\text { Age } \\
\text { Manchester Triage System }\end{array}$ & 1.02 & 1.06 to 2.05 & 0.001 \\
$\begin{array}{l}\text { Standard and non- } \\
\quad \text { urgent }\end{array}$ & - & Reference & 0.008 \\
$\quad \begin{array}{l}\text { Urgent } \\
\quad \begin{array}{l}\text { Immediate and very } \\
\text { urgent }\end{array}\end{array}$ & 2.02 & 1.25 to 3.26 & 0.004 \\
\hline $\begin{array}{l}\text { Baseline C reactive } \\
\text { protein }\end{array}$ & 1.002 & 1.001 to 1.003 & 0.009 \\
$\begin{array}{l}\text { Antecedent of kidney } \\
\text { disease }\end{array}$ & 1.58 & 1.02 to 2.45 & 0.04 \\
\hline
\end{tabular}

Independent variables included in the model: age, sex female $=0$ and male $=1$ ), diabetes mellitus ( $\mathrm{no}=0$ and yes $=1$ ), arterial hypertension ( $\mathrm{no}=0$ and yes $=1$ ), antecedent of cardiovascular disease ( $\mathrm{no}=0$ and yes $=1$ ), antecedent of kidney disease ( $\mathrm{no}=0$ and yes=1), Manchester Triage System Scale, leukocytes, lymphocytes, $C$ reactive protein, troponin I, invasive mechanical ventilation (no $=0$ and yes $=1$ ), intensive care unit admission ( $n o=0$ and yes $=1$ ), renal replacement therapy ( $\mathrm{no}=0$ and yes $=1$ ), coagulopathy complication (no $=0$ and yes $=1$ ), use of antibiotics ( $n o=0$ and yes $=1$ ) and use of steroids ( $\mathrm{no}=0$ and yes $=1$ ).

as lung, cardiovascular or kidney diseases and immunosuppression were found with similar frequencies than other reports, ${ }^{17-20}$ and all of them were more frequent in non-survivors.

Symptomatology was also similar to the previously reported, and only the presence of dyspnoea, in concordance with a more compromised respiratory function on admission (higher respiratory rate and lower pulse oximetry), was significantly more frequent in patients who died; interestingly, non-respiratory symptoms such as fever, cephalea and myalgia/arthralgia were more frequent in survivor patients.

Patients with COVID-19 hospitalised in our centre showed alteration in several haematological, biochemical, coagulation, and inflammatory biomarkers that have been associated with severe or fatal illness. ${ }^{24}$

Clinical management received by patients seemed to be similar in many aspects to other parts of the world. ${ }^{25}$ However, it was a lower use of azithromycin and hydroxychloroquine, and it was not different between survivors and non-survivors. Half of the patients received lopinavir/ ritonavir, but this antiviral was not associated with a better survival, in concordance with others. ${ }^{26}$ In addition, nearly $90 \%$ of patients in both groups had antithrombotic therapy with enoxaparin as it has been recommended in hospitalised patients, ${ }^{27}$ but no difference was found between survivors and non-survivors as reported in some previous cohort studies. ${ }^{28}{ }^{29}$ On the other hand, more non-survivor patients received antibiotics and steroids than survivors; a decision by treating doctors to use them in patients with more severe disease versus adverse effects cannot be ruled out.

One of the most relevant findings was the development of lung damage (respiratory failure and ARDS) as a marker of poor outcome. Patients who died suffered from a more severe respiratory damage as judged by the higher need for IMV and the shorter time they survived with such a therapy. The higher mortality among ventilated $(82 \%)$ versus non-ventilated patients $(18 \%)$ was similar to other series of critically ill patients. ${ }^{18} 21$ Non-survivor patients also have a more severe involvement of other organs, evidenced by development of acute kidney failure and the increase of several markers of cardiac involvement and procoagulant activity. Most patients that developed acute kidney failure were conservatively managed, and only $6 \%$ received a renal replacement therapy.

Besides the IMV due to respiratory insufficiency and the admission to ICU, older age, severity of disease at admission, baseline high CRP and antecedent of kidney disease were the main predictors for mortality in the multivariate analysis. In the light of these findings, higher attention and improvement of the management of IMV, kidney disease and the inflammatory storm in COVID-19 might be areas of opportunity to positively affect the outcome of in-hospital patients. Particularly in the latter issue, some therapies (ie, tocilizumab) ${ }^{30}$ may be promissory; however, in settings with limited economic resources as ours, high cost could be restrictive. Alternative anti-inflammatory treatments could be investigated.

A recent study in population without social security from the centre of Mexico ${ }^{31}$ showed a mortality rate $8 \%$ lower than the present study; besides the fact that ours was a population covered by social security, patients in this study also seemed to have more frequently diabetes and hypertension.

Our study has several limitations. Several variables such as the optimal use and efficacy of antivirals and antibiotics, adherence to high standards of supportive therapies (particularly IMV or renal replacement therapies) or others could not be exhaustively analysed in this study as data were collected exclusively by means of the electronic medical records. On the other hand, a large sample size from a single centre supports the internal validity of our results, but extrapolation to other settings needs to be investigated.

Due to the scarcity of data in one of the geographical area most affected by the COVID-19 pandemic, our results gain special relevance. Latin America and Mexico, in particular, are regions with high prevalence of non-communicable diseases, which are risk factors for SARS-CoV-2 infection. Moreover, socioeconomic problems may preclude the provision of the most updated means for high-standard management of severe cases, that is, the hospitalised patients. Our data are in concordance 
with others, ${ }^{31}$ suggesting that overcrowding and shortage of resources are highly contributing to mortality in settings like ours. Further research is needed to know the real implications of our findings in other areas or centres; meanwhile, they will contribute to a better understanding of COVID-19 in some places with similar conditions and probably help in the guidance for research and treatment strategies. Evidently, better specialised attention is needed to improve results, but emerging countries should also pay more attention in massive adoption of preventive measures against this disease.

In conclusion, mortality in hospitalised patients with COVID-19 in this centre of the west of Mexico seemed to be higher than in developed countries. These patients displayed a high frequency of risk factors for poor outcome, but the need for IMV, ICU admission, older age, more severe disease at admission, antecedent of kidney disease and higher CRP levels were the most significant predictive factors for mortality.

\section{Author affiliations}

${ }^{1}$ Unidad de Investigación Biomédica 02, Hospital de Especialidades Centro Médico Nacional de Occidente IMSS, Guadalajara, Mexico

${ }^{2}$ Dirección de Investigación y Educación, Hospital de Especialidades Centro Médico Nacional de Occidente IMSS, Guadalajara, Mexico

${ }^{3}$ División de Epidemiología Hospitalaria, Hospital de Especialidades Centro Médico Nacional de Occidente IMSS, Guadalajara, Mexico

${ }^{4}$ División de Tórax y Cardiovascular, Hospital de Especialidades Centro Médico Nacional de Occidente IMSS, Guadalajara, Mexico

${ }^{5}$ Departamento de Infectología, Hospital de Especialidades Centro Médico Nacional de Occidente IMSS, Guadalajara, Mexico

${ }^{6}$ Departamento de Admisión Médica Continua con Urgencias, Hospital de Especialidades Centro Médico Nacional de Occidente IMSS, Guadalajara, Mexico

${ }^{7}$ Dirección Médica, Hospital de Especialidades Centro Médico Nacional de Occidente IMSS, Guadalajara, Mexico

${ }^{8}$ Dirección General, Hospital de Especialidades Centro Médico Nacional de Occidente IMSS, Guadalajara, Mexico

Acknowledgements Our most sincere appreciation to the health personnel involved in the fight against COVID-19.

Contributors AMC-M, CA-R and HRH-G conceived the idea. AMC-M, MCE-B, SOH-G, ER-C, AHN-Z, CF-0, LMAB-P, AG-0, LC-S, MAM-R and JJR-M planned the investigation and acquired the data. AMC-M performed the data analysis. AMC-M wrote the manuscript with support of MCE-B, AHN-Z and ER-C. All authors (AMC-M, MCE-B, SOH-G, ER-C, AHN-Z, CF-0, LMAB-P, AG-0, LC-S, MAM-R, JJR-M, PEM-G, MA-M, RID-D-P, CA-R and HRH-G) interpreted and discussed results and contributed to the final manuscript.

Funding The authors have not declared a specific grant for this research from any funding agency in the public, commercial or not-for-profit sectors.

\section{Competing interests None declared.}

Patient and public involvement Patients and/or the public were not involved in the design, conduct, reporting or dissemination plans of this research.

\section{Patient consent for publication Not required.}

Ethics approval Due to the COVID-19 pandemic, the local Ethics in Research Committee No. 13018 approved this protocol and exempted the written informed consent. All patient data were handled anonymously and strictly confidential.

Provenance and peer review Not commissioned; externally peer reviewed.

Data availability statement All data relevant to the study are included in the article or uploaded as supplemental information. Data would be available from corresponding author on appropriate request.

Open access This is an open access article distributed in accordance with the Creative Commons Attribution Non Commercial (CC BY-NC 4.0) license, which permits others to distribute, remix, adapt, build upon this work non-commercially, and license their derivative works on different terms, provided the original work is properly cited, appropriate credit is given, any changes made indicated, and the use is non-commercial. See: http://creativecommons.org/licenses/by-nc/4.0/.

\section{ORCID iDs}

Alfonso M Cueto-Manzano http://orcid.org/0000-0002-0343-9508

María C Espinel-Bermúdez http://orcid.org/0000-0003-4539-8537

Sandra 0 Hernández-González http://orcid.org/0000-0001-6665-3950

Enrique Rojas-Campos http://orcid.org/0000-0001-6868-6465 Arnulfo H Nava-Zavala http://orcid.org/0000-0003-3061-521X Clotilde Fuentes-Orozco http://orcid.org/0000-0001-6230-8359 Luz Ma A Balderas-Peña http://orcid.org/0000-0002-5052-457X Alejandro González-0jeda http://orcid.org/0000-0003-2935-8703 Laura Cortes-Sanabria http://orcid.org/0000-0002-2828-3896 Mario A. Mireles-Ramírez http://orcid.org/0000-0002-8321-7883 José J Ramírez-Márquez http://orcid.org/0000-0001-7749-1002 Porfirio E Martínez-Gutiérrez http://orcid.org/0000-0003-2326-2911

Maribel Ávila-Morán http://orcid.org/0000-0002-4903-1671

Ramón I De-Dios-Pérez http://orcid.org/0000-0003-3181-3912

Carlos Acosta-Ramírez http://orcid.org/0000-0001-5391-1041

Hugo R Hernández-García http://orcid.org/0000-0001-7519-141X

\section{REFERENCES}

1 Coronaviridae Study Group of the International Committee on Taxonomy of Viruses. The species severe acute respiratory syndrome-related coronavirus: classifying 2019-nCoV and naming it SARS-CoV-2. Nat Microbiol 2020;5:536-44.

2 The World Health Organization. Available: https://www.who.int/dg/ speeches/detail/who-director-general-s-remarks-at-the-mediabriefing-on-2019-ncov-on-11-february-2020 [Accessed 30 Nov 2020].

3 Mahase E. Covid-19: WHO declares pandemic because of "alarming levels" of spread, severity, and inaction. BMJ 2020;368:m1036.

4 Johns Hopkins University of medicine. Available: https://coronavirus. jhu.edu/map.html [Accessed 3 Dec 2020].

5 Dong E, Du H, Gardner L. An interactive web-based dashboard to track COVID-19 in real time. Lancet Infect Dis 2020;20:533-4.

6 Gobierno de México. Secretaría de Salud. Available: https:// coronavirus.gob.mx/datos/ [Accessed 4 Dec 2020].

7 World Health Organization. Clinical management of COVID-19. Interim guidance (WHO/2019-nCoV/clinical/2020.5). Available: https://www.who.int/publications/i/item/clinical-management-ofcovid-19 [Accessed 1 Dec 2020].

8 Kalil AC, Metersky ML, Klompas M, et al. Management of adults with hospital-acquired and ventilator-associated pneumonia: 2016 clinical practice guidelines by the infectious diseases Society of America and the American thoracic Society. Clin Infect Dis 2016;63:e61-111.

9 Dugar S, Choudhary C, Duggal A. Sepsis and septic shock: Guideline-based management. Cleve Clin J Med 2020;87:53-64.

10 Kidney Disease: Improving Global Outcomes (KDIGO) Acute Kidney Injury Work Group. KDIGO clinical practice guideline. Kidney Int Suppl 2012;2:1-126.

11 Ranieri VM, Rubenfeld GD, Thompson BT. Acute respiratory distress syndrome: the Berlin definition. J Am Med Assoc 2012;307:2526-33.

12 Mackway-Jones K, Marsden J, Windle J. Emergency triage. John Wiley \& Sons, Ltd, 2014.

13 Seymour CW, Liu VX, Iwashyna TJ. Assessment of clinical criteria for sepsis for the third International consensus definitions for sepsis and septic shock (Sepsis-3). J Am Med Assoc 2016;315:762-74.

14 Zhang Z. Statistical description for survival data. Ann Trans/ Med 2016;4:401.

15 Ñamendys-Silva SA, Alvarado-Ávila PE, Domínguez-Cherit G, et al. Outcomes of patients with COVID-19 in the intensive care unit in Mexico: a multicenter observational study. Heart Lung 2021;50:28-32.

16 Socolovithc RL, Fumis RRL, Tomazini BM, et al. Epidemiology, outcomes, and the use of intensive care unit resources of critically ill patients diagnosed with COVID-19 in Sao Paulo, Brazil: a cohort study. PLoS One 2020;15:e0243269.

17 Zhou F, Yu T, Du R, et al. Clinical course and risk factors for mortality of adult inpatients with COVID-19 in Wuhan, China: a retrospective cohort study. Lancet 2020;395:1054-62.

18 Richardson S, Hirsch JS, Narasimhan M, et al. Presenting characteristics, comorbidities, and outcomes among 5700 patients 
hospitalized with COVID-19 in the New York City area. JAMA 2020;323:2052-9.

19 Grasselli G, Zangrillo A, Zanella A, et al. Baseline characteristics and outcomes of 1591 patients infected with sars-CoV-2 admitted to ICUs of the Lombardy region, Italy. JAMA 2020;323:1574-81.

20 Cates J, Lucero-Obusan C, Dahl RM, et al. Risk for in-hospital complications associated with COVID-19 and Influenza - Veterans Health Administration, United States, October 1, 2018-May 31, 2020. MMWR Morb Mortal Wkly Rep 2020;69:1528-34.

21 Silverio A, Di Maio M, Citro R, et al. Cardiovascular risk factors and mortality in hospitalized patients with COVID-19: systematic review and meta-analysis of 45 studies and 18,300 patients. BMC Cardiovasc Disord 2021;21:23.

22 Encuesta Nacional de Salud Y Nutrición (ENSANUT), 2018. Available: https://ensanut.insp.mx/encuestas/ensanut2018/informes.php [Accessed 5 Dec 2020].

23 Zhang P, Zhu L, Cai J, et al. Association of inpatient use of angiotensin-converting enzyme inhibitors and angiotensin II receptor blockers with mortality among patients with hypertension hospitalized with COVID-19. Circ Res 2020;126:1671-81.

24 Henry BM, de Oliveira MHS, Benoit S, et al. Hematologic biochemical and immune biomarker abnormalities associated with severe illness and mortality in coronavirus disease 2019 (COVID-19): a meta-analysis. Clin Chem Lab Med 2020;58:1021-8.
25 Pascarella G, Strumia A, Piliego C. COVID-19 diagnosis and management: a comprehensive review. J Intern Med 2020;13.

26 Cao B, Wang Y, Wen D, et al. A trial of Lopinavir-Ritonavir in adults hospitalized with severe Covid-19. N Engl J Med 2020;382:1787-99.

27 Gerotziafas GT, Catalano M, Colgan M-P, et al. Guidance for the management of patients with vascular disease or cardiovascular risk factors and COVID-19: position paper from VAS-European independent Foundation in Angiology/Nascular medicine. Thromb Haemost 2020;120:1597-628.

28 Tremblay D, van Gerwen M, Alsen M, et al. Impact of anticoagulation prior to COVID-19 infection: a propensity score-matched cohort study. Blood 2020;136:144-7.

29 Russo V, Di Maio M, Attena E, et al. Clinical impact of preadmission antithrombotic therapy in hospitalized patients with COVID-19: a multicenter observational study. Pharmacol Res 2020;159:104965

30 Toniati P, Piva S, Cattalini M, et al. Tocilizumab for the treatment of severe COVID-19 pneumonia with hyperinflammatory syndrome and acute respiratory failure: a single center study of 100 patients in Brescia, Italy. Autoimmun Rev 2020;19:102568.

31 Olivas-Martínez A, Cárdenas-Fragoso JL, Jiménez JV, et al. Inhospital mortality from severe COVID-19 in a tertiary care center in Mexico City; causes of death, risk factors and the impact of hospital saturation. PLoS One 2021;16:e0245772. 